\title{
Property-Denoting NPs and Non-Canonical Genitive Case
}

\author{
Olga Kagan \\ Hebrew University of Jerusalem
}

\section{Introduction}

In this paper, I discuss the semantics of certain instances of non-canonical genitive Case in Russian. I use the term non-canonical genitive Case to refer to the phenomena whereby an object of the verb is assigned genitive Case, rather than accusative. More specifically, I discuss two phenomena: Genitive of Negation and Intensional Genitive. The paper is organized as follows. First, I introduce the two phenomena. In Section 2, I demonstrate that they share numerous properties and, therefore, a unifying account is preferable. Previously proposed analyses of non-canonical genitive Case are briefly discussed in Section 3. In Section 4, I propose a new direction for analyzing the phenomena in question. I present part of my on-going research on the topic and argue that the choice of the Case of the object in the discussed environments is dependent on existential commitment. I suggest that this notion, once appropriately elaborated, makes it possible to account for both the distribution of genitive objects and their semantic properties. Finally, in Section 5, the relation between absence of existential commitment and the semantics of NPs is examined. It is proposed that NPs that lack existential commitment in the sense formulated in Section 4 denote properties, rather than referring to or quantifying over objects in any given world. I therefore propose that the non-canonical genitive Case is assigned to propertydenoting NPs.

\subsection{Genitive of Negation}

Genitive of Negation is a well-documented phenomenon whereby a non-oblique internal argument of the verb, which is generally assigned accusative Case, as in (1a), can be optionally assigned genitive Case under negation, as is exemplified in (1b).
a. Ja pil vodu / *vody
I drank water(acc) / (gen)
'I drank water / I was drinking water.'
b. Ja ne pil vodu/vody.
I NEG drank water(acc)/(gen)
'I didn't drink water.'

I wish to thank Edit Doron, Donka Farkas, Ede Zimmermann, Yael Sharvit, Fred Landman and Ariel Cohen for fruitful discussions. I am also grateful to the audience of IATL 21, Logic and Language 9 and SALT 17 for important comments and questions. All mistakes are my own. 
Under negation, the NP voda 'water' can appear either in the accusative or in the genitive Case. Importantly, in the corresponding affirmative clause in (1a), only accusative Case is possible. Thus, it is negation that licenses the assignment of the genitive Case.

\subsection{Intensional Genitive}

The second phenomenon to be analyzed in this paper is Intensional Genitive. This is the phenomenon whereby certain intensional verbs license both genitive and accusative Case-marking on their direct objects. These verbs include verbs meaning "to wish", "to want", "to deserve", "to ask for", "to demand", "to wait for" and others. The phenomenon is exemplified in (2).
a. On ždal čuda / Dimu.
He waited miracle(gen) / Dima(acc)
'He was waiting for a miracle / for Dima.'
b. Ty zasluživaeš medali / medal'. You deserve medal(gen sg)/(acc sg)
'You deserve a medal.'

In (2a), the NP čuda 'a miracle' appears in the genitive Case. In contrast, the NP Dima is obligatorily marked accusative Case. In (2b), the NP medal' 'a medal' can appear in either accusative or genitive Case.

It can be seen that with intensional verbs, the genitive Case-assignment is not always optional. In some sentences, it is obligatory, in some sentences, optional, and sometimes only accusative Case can be assigned.

It should also be pointed out that not all intensional predicates ever license genitive Case-marking on their objects. For instance, the object NPs of such verbs as predvidet' 'foresee' and predstavljat' 'imagine' are obligatorily accusative. An account of these restrictions will be provided in Section 4.3 below.

\section{Intensional Genitive and Genitive of Negation as a Single Phenomenon}

Genitive of Negation is discussed in the literature much more often than Intensional Genitive and is normally given an analysis independently from the second phenomenon. However, following Neidle (1988), I believe that a unifying analysis should be proposed. This conclusion is drawn on the basis of numerous similarities that hold between the two phenomena.

Firstly, both phenomena constitute a genitive/accusative alternation in the Case of the object.

Secondly, the same semantic factors appear to affect the choice of Case within both phenomena. Before I turn to listing these factors, it is important to emphasize that all of them merely constitute tendencies in the choice of Case. The existence of some of these tendencies has been noted by Timberlake (1986), Neidle (1988), Bailyn (1997) and Babyonyshev (2003), among others. 


\section{i) Abstract / Concrete}

Firstly, abstract nouns are more likely to be assigned genitive Case than concrete ones. This tendency is demonstrated in (3) for Genitive of Negation and in (4-5) for Intensional Genitive.

(3) a. On ne našol ???sčast'je / sčast'ja. he NEG found happiness(acc)/(gen)

'He didn't find happiness.'

b. On ne našol cvetok/ ???cvetka.

he NEG found flower(acc sg)/(gen sg)

'He didn't find a / the flower.'

(4) a. Dima ždjot čuda / *čudo.

Dima waits miracle(gen sg)/(acc sg)

'Dima is waiting for a miracle.'

b. Dima ždjot posylku / *posylki.

Dima waits parcel( $\mathrm{acc} \mathrm{sg}) /(\mathrm{gen} \mathrm{sg})$

'Dima is waiting for a parcel.'

(5) a. on iščet prikliučenij / ?priključenija

he seeks adventures(gen $\mathrm{pl}) /(\mathrm{acc} \mathrm{pl})$

'He is seeking adventures.'

b. on iščet knigi / *knig.

he seeks books(acc pl)/(gen pl)

'He is seeking books.'

ii) Number

In addition, genitive is more often assigned to plural NPs than to singular ones.

Thus, Genitive of Negation is acceptable in (6a) but not in (6b). Similarly, most of my informants accept (7a), under the meaning according to which the speaker is waiting for a plant to blossom, but not (7b), its counterpart with a singular object.

(6) a. Ja ne našol cvety / cvetov.

I NEG found flowers(acc pl)/(gen pl)

'I didn't find (the) flowers.'

b. Ja ne našol cvetok/ ???cvetka.

I NEG found flower(acc sg)/(gen sg)

'I didn't find a / the flower.'

(7) a. Ja ždu cvetov.

(Timberlake 1986:342)

I wait flowers(gen pl)

'I am waiting for flowers.'

b. ??? Ja ždu cvetka.

I wait flower(gen sg)

'I am waiting for a flower.'

iii) Definiteness

Thirdly, genitive is more likely to be assigned to indefinite NPs than to definite ones. The NP novyje ukrašenija 'new jewels' is more likely to appear in the 
genitive Case than eti ukrašenija 'these jewels' in (8) and (9).

(8) a. Lena ne kupila eti ukrašenija / ???etix ukrašenij Lena NEG bought [these jewels](acc pl)/(gen pl)

'Lena didn't buy these jewels.'

b. Lena ne kupila novyje ukrašenija / novyx ukrašenij. Lena NEG bought [new jewels] (acc pl)/(gen pl) 'Lena didn't buy new jewels.'

(9) a. Lena potrebovala eti ukrašenija / ???etix ukrašenij Lena demanded [these jewels] (acc pl)/(gen pl)

b. Lena potrebovala novyje ukrašenija / novyx ukrašenij. Lena demanded [new jewels] (acc pl)/(gen pl)

iv) Proper / Common

Among definite NPs, proper names are less likely to be marked genitive than NPs headed by common nouns. Thus, the proper name Lena in (10a) cannot appear in the genitive Case, in contrast to the definite NP etot razgovor 'this talk' in (10b), which contains a demonstrative. A similar pattern holds in (11). The proper name functioning as the object of the intensional verb ždat' 'wait' is obligatorily accusative. In contrast, the definite NP eta vstreča 'this meeting' is at least preferable in the genitive Case.

(10) a. Petja ne pomnit Lenu / *Leny. Petja not remember Lena(acc)/(gen)

b. Petja ne pomnit etot razgovor/ etogo razgovora. Petja not remember [this talk] (acc sg)/(gen sg) 'Petja doesn't remember this talk.'

(11) a. Ivan ždjot Annu / *Anny. Ivan waits Anna(acc)/(gen) 'Ivan is waiting for Anna.'

b. Ivan ždjot ???etu vstreču / etoj vstreči. Ivan waits this meeting( $\operatorname{acc} \mathrm{sg}) /($ gen sg) 'Ivan is waiting for this meeting.'

v) Specificity and Scope

In addition, genitive NPs are normally interpreted as non-specific and taking narrow scope. Their accusative counterparts may be interpreted as either specific or not. (The examples in 12 are taken from Harves 2002.)

(12) a. Anna ne kupila knigi. Anna NEG bought books(acc pl)

'Anna didn't buy (the) books.'

b. Anna ne kupila knig. Anna NEG bought books(gen pl)

'Anna didn’t buy (any) books.' 
a. Dima iščet švedskije marki.

Dima seeks [Swedish stamps](acc pl)

'Dima is seeking Swedish stamps.'

b. načal'nik trebujet pribyli.

boss demands profit(gen)

'The boss demands profit.'

Thus, (12b) entails that Anna did not buy any books. The object NP obligatorily receives a non-specific, narrow scope interpretation. In turn, (12a), in which the object is accusative, is ambiguous. Under its salient reading, it means that there is a particular set of books (possibly but not necessarily familiar from the context) that Anna did not buy. In this case, the indefinite NP takes wide scope relative to the negative operator. The second, less salient meaning of the sentence is essentially identical to the one available to (12b), as discussed above.

In turn, consider the sentences in (13), which contain intensional verbs. (13a) may either mean that Dima is looking for a particular set of Swedish stamps or that he is interested in any stamps from Sweden. In turn, the object NP in (13b) may only get a non-specific, narrow scope reading. This sentence means roughly that the boss demands that the employees work in such a way that there be profit.

vi) Existential Commitment

Finally, Case-assignment within both phenomena is equally sensitive to existential commitment. I assume that an NP carries existential commitment iff the sentence in which it appears either entails or presupposes that the NP quantifies over a non-empty set (or has a referent, in case the NP in question is individual-denoting rather than quantificational).

Both under negation and following intensional predicates, genitive NPs lack existential commitment, in contrast to accusative objects, for which existential commitment is certainly possible, though not obligatory.

a. Dima ne našol sledy.

Dima not found traces(acc pl)

Dima didn't find the/any traces.

b. Dima ne našol sledov.

Dima not found traces(gen pl)

'Dima didn't find any traces.'

If the object NP appears in the accusative Case, as in (14a), the sentence suggests that relevant traces were actually left, but Dima failed to find them. In contrast, if the NP is genitive, the possibility becomes salient that no traces were left, and that is why, naturally, Dima did not find any. It should be emphasized that accusative NPs do not always carry existential commitment; this is only a tendency. Genitive objects, in turn, strongly tend to lack such a commitment.

Let us now turn to complements of opaque verbs. The fact that accusative NPs are compatible with existential commitment is revealed in (11a), in which a proper name appears in the accusative Case. The sentences in (15), in turn, 
demonstrate the fact that genitive NPs do not normally carry a commitment to existence. (15a) means that the speaker will be waiting for the addressee's new stories to be written; namely, the object NP does not have a referent in the actual world. According to my informants, the sentence does not mean that the speaker is waiting to receive copies of already existing stories. In turn, (15b) can be uttered in the following context: the water is currently cold, and Lena has turned on a boiler in order to heat it. Crucially, according to this reading, the NP hot water does not refer to an entity that exists in the actual world. Thus, existential commitment is absent.

a. Ja budu s neterpeniem ždat' vašix novyx rasskazov.

I will with impatience wait [your new stories](gen pl)

'I will be waiting impatiently for your new stories.'

b. Lena ždjot gorjačej vody.

Lena waits hot(gen) water(gen)

'Lena is waiting for a hot water.'

I have listed a number of properties that affect Case-assignment both to complements of opaque verbs and to objects under negation.

An additional similarity between Genitive of Negation and Intensional Genitive has to do with the fact that both phenomena are associated with a considerable amount of variation in native speakers' judgments. Thus, native speakers of Russian often disagree as to whether an NP can appear in the genitive Case in a given sentence or not. It is important to point out that speakers who are relatively reluctant to accept Genitive of Negation are similarly reluctant to accept Intensional Genitive. Such a variation does not normally characterize judgments related to Case-assignment. This factor is probably a by-product of the process of language change taking place in Russian, which is also mentioned by Neidle. She notes that, within both phenomena under discussion, accusative Case is used now with increasing frequency.

Finally, it appears that across Balto-Slavic languages, there is a strong correlation between the presence and the obligatoriness of Genitive of Negation on the one hand and of Intensional Genitive on the other. Thus, in those languages, in which Genitive of Negation is obligatory, opaque verbs in question generally consistently take genitive objects. In those languages in which Genitive of Negation is optional as it is in Russian, opaque verbs also license both genitive and accusative objects. Finally, if Genitive of Negation is essentially absent in a language, Intensional Genitive is also absent, most intensional verbs normally taking accusative complements. There do exist certain exceptions to this correlation, however. (Thus, in Slovenian, Genitive of Negation is obligatory, but Intensional Genitive is optional, and in Polish, both phenomena are generally obligatory, but there do exist certain opaque verbs that license accusative Casemarking.) The facts are summarized in Table 1 below.

On the basis of this discussion I conclude that Genitive of Negation and Intensional Genitive constitute different instantiations of the same phenomenon, which I will refer to as Irrealis Genitive. 


\begin{tabular}{|l|l|l|}
\hline Language & Genitive of Negation & Intensional Genitive \\
\hline Old Church Slavonic & obligatory & obligatory \\
\hline Lithuanian & obligatory & obligatory \\
\hline Russian & optional & optional \\
\hline Ukrainian & optional & optional \\
\hline Belarusian & optional & optional \\
\hline Latvian & optional & optional \\
\hline Serbo-Croatian & essentially absent & essentially absent \\
\hline Czech & essentially absent & essentially absent \\
\hline Slovenian & obligatory & optional \\
\hline Polish & obligatory & ?obligatory / ?optional \\
\hline
\end{tabular}

Table 1

\section{Previous Analyses}

It should be pointed out that Genitive of Negation has received much more attention in the literature than Intensional Genitive, and, thus, numerous analyses that focus on the former phenomenon do not make reference to the latter. In addition, most of these analyses are syntactic, focusing on the mechanism by which the genitive and accusative Case-features are checked (e.g. Bailyn 1997).

One of the exceptions, a unified account of the two phenomena that makes reference to both syntactic and semantic properties involved, is provided by Neidle (1988). Neidle proposes that the choice of Case is determined by the [Quantifying] feature $([+/-\mathrm{Q}])$. The feature $[+\mathrm{Q}]$ is contributed to the VP node both by the negation operator and by opaque verbs, and it functions as a scope marker. This feature further spreads to the object NP if the latter appears within the scope of the operator. In this case, the object will be marked genitive. In contrast, the feature $[+\mathrm{Q}]$ will not spread to an NP that takes wide scope relative to negation or an opaque verb. Such an NP will appear in the accusative Case.

The fact that this approach allows for a unifying account of Genitive of Negation and Intensional Genitive is an important advantage of this analysis. However, it has two substantial shortcomings. Firstly, scope relations are not sufficient to account for the Case alternation in either of the two phenomena since accusative NPs can take both narrow and wide scope relative to negation or an opaque verb. Secondly, it is not perfectly clear why the [Quantifying] feature should be contributed by negation and opaque verbs but not by other quantificational operators, such as, for instance, the generic operator. An NP can appear either within or outside the scope of such an operator; still, genitive Caseassignment to objects is not licensed in generic and habitual sentences.

\section{Irrealis Genitive and Existential Commitment: The Proposal}

The sensitivity of the choice of Case to the semantic properties of the NP, even in those cases in which they do not seem to affect the syntactic configuration in any 
important way, suggests that the assignment of Irrealis Genitive is indeed semantically restricted. I propose, following in part the discussion in Section 2, that the key property to which the Case-marking pattern is sensitive is commitment to existence - crucially, not only existence in the actual world but also in any given possible world that is made salient in the sentence (in the sense to be specified below). For instance, John didn't find (any) documents neither entails nor presupposes that (relevant) documents exist in the actual world, nor in any particular alternative version of reality introduced in the sentence.

Below, I will argue that the distribution of Irrealis Genitive is determined by the following restriction: An NP may appear in this Case if and only if it lacks commitment to existence in any given possible world that is made salient in the given sentence. In Sections 4.1 and 4.2 below, I clarify the relevant notions that make it possible to distinguish existential commitment in the traditional sense of the term (i.e. commitment that an NP quantifies over a nonempty set in the actual world) and a weaker version of existential commitment - namely, a commitment that the relevant set is not empty in some salient version of reality which may differ from $\mathrm{w}_{0}$. In Section $4.3 \mathrm{I}$ formulate the rule that restricts the distribution of Irrealis Genitive Case. Then, in Sections 4.4 and 4.5, I demonstrate how this restriction accounts for the distribution of genitive objects and for their semantic properties, respectively.

\subsection{Assertions and Possible Worlds}

I assume that by default, a sentence constitutes an assertion about the actual world. Even if a given sentence contains a modal operator, the assertion as a whole is still valid for $\mathrm{w}_{0}$. Thus, (16) does not entail that the speaker's sister is at home at $\mathrm{w}_{0}$; however, her possibly being at home is claimed to be true in $\mathrm{w}_{0}$.

My sister may be at home.

Similarly, presuppositions contributed by various constituents in a sentence tend to contain information about reality. Thus, the subject NP in (16) presupposes that the speaker has a sister in the actual world.

Still, as discussed extensively by Farkas (1985, 2003) and Heim (1992), among others, sentences may contribute information about possible worlds other than the actual one. For instance, consider such intensional verbs as think and believe. Sentences that contain these verbs make an assertion not only about $\mathrm{w}_{0}$ but also about those worlds that conform to the vision of reality of the attitude holder.

(17) Mary thinks that a unicorn entered her house.

(17') think (Mary, Jx [unicorn (x) $\wedge$ enter (x, Mary's-house)])

Thus, (17) as a whole makes an assertion about the actual world: it is in the actual world that Mary is entailed to have a certain belief. In addition, however, the sentence makes an assertion about a set of alternative versions of reality, in 
particular, the worlds that represent Mary's beliefs. (17) entails that in every possible world which conforms to Mary's worldview, it holds that a unicorn entered Mary's house. (Thus, 17' is essentially equivalent to 17" below.) Quantification over this particular set of worlds is introduced by the intensional verb thinks.

$\forall \mathrm{w}\left[\mathrm{w} \in \mathrm{W}_{\mathrm{M}, \mathrm{wo}} \rightarrow \exists \mathrm{x}\right.$ [unicorn $(\mathrm{x}, \mathrm{w}) \wedge$ enter (x, Mary's-house,w)])] where $\mathrm{W}_{\mathrm{M} \text {,wo }}$ stands for the set of all possible worlds that conform to Mary's vision of reality

Thus, in (17), the intensional verb introduces an accessibility relation to a certain set of worlds, and the embedded proposition is asserted to be true in these worlds. The state of affairs is not the same with all modal or intensional operators. For instance, Heim (1992) and Farkas (2003) distinguish two types of intensional verbs that differ crucially in the relevant respect. Thus, according to Heim, such verbs as think and believe do contribute an assertion about a particular set of worlds (one that represents the beliefs of the attitude holder, as discussed above). These verbs introduce an accessibility relation to a certain set of worlds, in which their complement is asserted to hold. Following the terminology in Farkas (2003), I will refer to verbs of this class as strong intensional verbs. In addition to such verbs as think and believe, this class includes reported assertion predicates (e.g. say) and fiction predicates (e.g. dream and imagine). In contrast, the complement of desiderative predicates such as want is not entailed to be true in any given set of worlds. Rather, intensional predicates of this type trigger a world ranking, whereby the worlds in which the proposition contributed by the complement clause is true are ordered higher than the ones in which it is false. According to this view, a sentence like John wants to find a unicorn does not introduce a set of worlds in which the proposition John finds a unicorn is asserted to hold. Rather, it asserts that, as far as John is concerned, those worlds in which the latter proposition is true are ranked higher than the ones in which it is not. Verbs of the latter type are classified by Farkas (2003) as weak intensional verbs.

Thus, some intensional operators introduce sets of possible worlds in which the embedded propositions are entailed to be true, whereas others do not, their semantic contribution being of a different nature. As discussed by Farkas (2003), this contrast has important consequences for the choice of mood in the embedded clause. In particular, weak intensional verbs, but not strong ones, license subjunctive mood. In Section 4.4 of this paper, it will be revealed that the same distinction affects the choice of Case in Russian.

\subsection{Absolute and Relative Existential Commitment}

As discussed in the previous section, a sentence may involve assertions made not only about the actual world but also about alternative versions of reality introduced by a modal or intensional operator. Similarly, an NP that appears in such a sentence may carry commitment to existence in the actual world or in any of these alternative possible worlds. 
By default, in the absence of an intensional or non-veridical operator, an NP carries commitment to existence in the actual world. For instance, (19a) entails and (19b) presupposes (19'), i.e. the existence of at least one green dog in $\mathrm{w}_{0}$.

a. Mary patted a green dog.

b. Mary patted the green dog.

Gx $[\operatorname{dog}(\mathrm{x}) \wedge \operatorname{green}(\mathrm{x})]$

In the presence of a non-veridical or intensional operator, existential commitment of this type can be canceled. However, in most cases, it will be substituted by a commitment that the NP in question has a referent in some alternative possible world which is introduced in the sentence. For instance, (17), repeated below, does not entail the existence of a unicorn in $\mathrm{w}_{0}$. This results from the fact that the indefinite NP is interpreted within the scope of an intensional predicate. However, the sentence does entail that there exists at least one unicorn in all those worlds that are compatible with Mary's beliefs. The same verb that cancels existential commitment in $\mathrm{w}_{0}$ introduces a set of worlds relative to which existential commitment is present.

(17) Mary thinks that a unicorn entered her house.

An analogous example is provided in (20), which contains an epistemic possibility operator.

(20) A unicorn may have entered the house.

$\left(20^{\prime}\right) \diamond \exists x[$ unicorn $(\mathrm{x}) \wedge$ entered $(\mathrm{x}$, the-house)]

(20") ヨw $\exists x[$ unicorn $(\mathrm{x}, \mathrm{w}) \wedge$ entered $(\mathrm{x}$, the-house, $\mathrm{w})]$

Under the salient reading of the sentence, represented by two equivalent formulae $\left(20^{\prime}\right)$ and (20"), the subject NP is interpreted within the scope of the modal may. As a result, the sentence does not entail existence of a unicorn in the actual world. However, the sentence involves quantification over a set of possible worlds, in this case, the epistemically accessible worlds (at least under the most likely interpretation). It entails that in at least one of these worlds, it is true that a unicorn entered the house. This, in turn, entails that in at least one of these worlds, a unicorn does exist. Thus, while existential commitment relative to the actual world is absent, we do find commitment to existence in (an)other possible world(s).

As will be demonstrated in the next section, this latter notion of relativized existential commitment is important for explaining the distribution of Irrealis Genitive. Therefore, for the current purposes, I will distinguish two types of commitment to existence, defined below. Absolute Existential Commitment (AEC) is existential commitment in the traditional sense, i.e. a commitment to existence in the actual world. In turn, the term Relative Existential Commitment (REC) captures the notion that has been introduced in this section: this is a commitment to existence in $\mathrm{w}_{0}$ or in any alternative possible world that stands to 
it in an accessibility relation introduced in the sentence. (An accessibility relation may be introduced by a modal or intensional operator, e.g. a propositional attitude verb, e.g. think, or a modal verb, e.g. should, may.) In the definition (21) below all such worlds are subsumed under the set $\mathrm{W}^{\mathrm{S}}$. Essentially, REC is commitment to existence in those possible worlds about which an assertion is being made in the sentence, or relative to which the sentence contains presuppositions.

(21) Let $\mathrm{S}$ be a sentence with propositional content $\mathrm{p}$. Let NP be a noun phrase that contributes the property $\mathrm{P}$. Let $\mathrm{w}_{0}$ be the actual world. Let $\sim$ encode entailment and/or presupposition relation.

a. An occurrence of an NP in S carries Absolute Existential Commitment iff $\mathrm{p} \sim \exists \mathrm{x} \mathrm{P}\left(\mathrm{x}, \mathrm{w}_{0}\right)$

b. An occurrence of an NP in S carries Relative Existential Commitment iff $\exists w\left[w \in W^{S} \wedge p \sim \exists x P(x, w)\right]$

It can be seen from (21) that an NP that carries AEC, obligatorily carries REC as well. The actual world is always by default included in the set $\mathrm{W}^{\mathrm{S}}$, and therefore, once commitment to existence in the actual world is present, it necessarily follows that there is existential commitment relative to at least one world in $\mathrm{W}^{\mathrm{S}}$.

As illustrated in (17) and (20) above, in the vast majority of cases, an NP that lacks AEC is still characterized by REC. However, within the scope of certain operators, even REC may be absent. In the next section, I argue that Irrealis Genitive Case can be assigned only to those NPs that lack REC.

\subsection{Irrealis Genitive and Relative Existential Commitment}

As has been demonstrated in Section 2 above, NPs that appear in Irrealis Genitive Case consistently lack Absolute Existential Commitment. Importantly, these NPs must lack Relative Existential Commitment as well.

First, it should be pointed out that both negation and the intensional verbs that license Irrealis Genitive cancel REC. Thus, consider the sentences in (22):

a. Mary is waiting for a miracle.

b. Mary didn't find a solution to the problem.

(22a) does not entail the existence of the relevant miracle in the actual world, nor does it entail that the miracle has taken place in an alternative version of reality which is, in some way or other, introduced into the picture by the verb wait. For instance, the sentence does not entail that the miracle has taken place in the worlds that conform to Mary's view of reality (on the opposite, the fact that Mary is waiting for the miracle means that she believes it has not yet taken place). In this sense wait belongs to the same class of intensional verbs as want, whose properties have been discussed in section 4.1: its complement is not entailed to hold in any particular possible world. Rather, it introduces a ranking of possible worlds relative to a certain anchor (the subject of the sentence). According to 
(22a), worlds in which the relevant miracle takes place are ranked higher than the ones in which it doesn't. But existential commitment of any type is absent.

Similarly, REC does not characterize the indefinite NP in (22b). Negation cancels AEC of the NP that is interpreted within its scope: the sentence does not entail that in the actual world, there exists a solution to the problem in question. In addition, the negative operator does not introduce any alternative possible worlds in which such a solution is entailed (or presupposed) to exist.

It can thus be observed that, unlike most intensional and non-veridical operators, negation and certain intensional verbs can cancel REC. This, I believe, explains the fact that Irrealis Genitive is licensed specifically by these operators. I propose that the assignment of Irrealis Genitive Case is subject to the restriction formulated in (23) below:

An NP that appears in the direct object position in a sentence S may be assigned Irrealis Genitive Case iff $\neg$ G $w\left[\mathrm{w} \in \mathrm{W}^{\mathrm{S}} \wedge \mathrm{p} \sim \exists \mathrm{x} \mathrm{P}(\mathrm{x}, \mathrm{w})\right]$

(where $\mathrm{S}, \mathrm{W}^{\mathrm{S}}$, $\mathrm{p}$ and $\mathrm{P}$ are as in 21 above)

Essentially, (23) states that NPs that appear in Irrealis Genitive must lack REC. This restriction accounts for both the distribution and the semantic properties of genitive objects, as is revealed below.

\subsection{Distribution}

Firstly, the approach to Irrealis Genitive developed above captures the fact that this Case is licensed specifically by negation and intensional predicates, since these constitute the rare operators that cancel REC, as discussed above.

In addition, the notion of REC makes it possible to account for the fact that some intensional verbs but not others can take genitive complements. Table 2 below lists a number of Russian intensional verbs, dividing them into two groups. The verbs in the left column license Irrealis Genitive; the verbs in the right column do not.

\begin{tabular}{|l|l|}
\hline $\begin{array}{l}\text { Opaque Verbs that License Genitive } \\
\text { Case-Assignment }\end{array}$ & $\begin{array}{l}\text { Opaque Verbs that do not License } \\
\text { Genitive Case-Assignment }\end{array}$ \\
\hline $\begin{array}{l}\text { xotet' (want), želat' (wish), žaždat' } \\
\text { (thirst for), trebovat' (demand), prosit' }\end{array}$ & $\begin{array}{l}\text { predvidet' (foresee), predskazyvat' } \\
\text { (foretell), predstavljat' (imagine), }\end{array}$ \\
(ask for), ždat' (wait), ožidat' (wait, & $\begin{array}{l}\text { risovat' (paint), izobražat' (picture), } \\
\text { expect), iskat' (look for, seek), izbegat' } \\
\text { napominat' (remind, resemble), } \\
\text { (avoid), zasluživat' (deserve), stoit' } \\
\text { planirovat' (plan), obeščat' (promise) } \\
\text { (cost, be worth), bojat'sja (be afraid of) }\end{array}$ \\
\hline
\end{tabular}

Table 2

The verbs that appear in the right column are strong intensional predicates, which, similarly to think, introduce sets of possible worlds in which their complement is 
entailed to hold. For instance, the verb predvidet' 'foresee' introduces a set of worlds that are compatible with the subject's view of the future. Consequently, complement NPs of these verbs carry REC: they are entailed to quantify over a non-empty set in those possible worlds that are introduced by the predicate. For instance, (24), whose formal representation is provided in (24'), entails (24"); in other words, it entails the existence of a thunderstorm in all the possible worlds that conform to Masha's vision of the future. (24' and 24" are essentially equivalent.)

(24) Maša predvidit grozu.

Masha foresees thunderstorm(acc sg)

'Masha foresees a thunderstorm.'

(24') forsees (Masha, $\exists x$ (thunderstorm, $\mathrm{x}$ ))

(24") $\forall \mathrm{w}\left[\mathrm{w} \in \mathrm{W}_{1} \rightarrow \exists \mathrm{x}\right.$ (thunderstorm, $\mathrm{x}, \mathrm{w}$ )]

where $\mathrm{W}_{1}$ is the set of all possible worlds that conform to Masha's

vision of the future.

Thus, by the definition in (21b), the object NP carries REC. This is why Irrealis Genitive is not licensed.

In contrast, the verbs in the left column of Table 2 constitute weak intensional predicates. The Romanian counterparts of most of these verbs are classified as such by Farkas; all the verbs in this column license subjunctive mood. These verbs do not introduce possible worlds in which their complement clauses are entailed to be true but rather trigger world ranking. When they take nominal complements, the latter are allowed to lack commitment to existence in any particular world. For instance, none of the variants of (25) entails the existence of the relevant answer in any given version of reality:

On ždjot / trebujet / zasluživaet otveta.

He waits / demands / deserves answer(gen sg)

'He is waiting for / demands / deserves an answer.'

The verbs do introduce an accessibility relation to worlds in which their clausal complements would be entailed to hold and their nominal complements, to exist. Thus, in (25), REC is absent and Irrealis Genitive, available.

It can thus be seen that the distinction between weak and strong intensional predicates together with the restriction in (23) above predicts correctly which intensional verbs license genitive objects and which do not.

Let us now turn to genitive Case-assignment under negation. A close look reveals that not every negated verb licenses Irrealis Genitive objects either. In particular, this Case is unavailable if the verb, by some mechanism or other, triggers an existential presupposition of its complement. For instance, the sentences in (26) are judged unacceptable by my informants, despite the fact that the genitive NPs are plural and may (or even have to) receive non-specific, indefinite, narrow scope readings. In other words, in terms of their semantic 
properties, the NPs seem to be perfectly compatible with the assignment of Irrealis Genitive.
a. *On ne perečityval otvetov.
He NEG reread answers(gen pl)
'He didn't reread answers.'
b. ???Obyčno ja ne otstiryvaju pjaten.
Generally I NEG wash-out stains(gen pl)
'Generally, I don't (succeed to) take stains out.'

These sentences become acceptable once the genitive NPs are substituted by their accusative counterparts.

Consider (26a). The verb perečityvat' 'reread', similarly to its English counterpart, triggers a presupposition that one reading event has already taken place. Thus, the sentence (27), whose logical form is provided in (27'), presupposes that John has read the answer in question at least once before (27").

(27) John reread an answer.

(27') Gx [answer $(\mathrm{x}) \wedge$ reread (John, $\mathrm{x})]$

entailment

(27") $\exists x$ [answer $(\mathrm{x}) \wedge \operatorname{read}($ John, $\mathrm{x})]$

presupposition

The existence of an answer is entailed not only by (27') but also by (27"). Since (27") constitutes a presupposition, it follows that the existence of the answer is both entailed and presupposed by (27).

Once the sentence is negated, as in (28), $\left(27^{\prime}\right)$ is no longer entailed, and the sentence no longer entails the existence of a relevant answer.

\section{John didn't reread an answer.}

However, presuppositions are generally sustained under negation, unless metalinguistic negation is involved (Horn 1989, among others); therefore, (31) does presuppose that one event of John reading the answer has taken place. The speaker denies a repetition of this event, but does assume that one reading event did occur. In other words, while (27') is no longer entailed, (27") is still presupposed. This, in turn, means that (28) does presuppose the existence of the relevant answer. (If John has read an answer once, then the answer has to exist.) This means that the object NP keeps carrying existential commitment under negation, by virtue of the properties of the verb reread. By this mechanism, the object NP in (26a) carries existential presupposition. For this reason, it cannot appear in Irrealis Genitive: it is characterized by existential commitment.

The same holds for (26b). The verb otstiryvat' 'wash out' presupposes the existence of stains to be taken out. Under its salient reading, the sentence asserts that in those situations in which clothes are stained, the speaker does not succeed to take out the latter (or does not even try to). Thus, existential commitment is present. 
(It has been suggested to me by one speaker that $26 \mathrm{~b}$ may, in fact, be acceptable with the genitive object, in which case it has to be interpreted as: Taking out stains is not a kind of activity that I engage in. Note that under this reading, existence of any stains is not presupposed.)

To sum up, it can be concluded that Irrealis Genitive Case is not available under negation as long as the predicate contributes an existential presupposition to its complement. This generalization further supports the claim that Irrealis Genitive is licensed if and only if existential commitment of any type is absent.

\subsection{Semantic Properties}

In addition to accounting for the distribution of Irrealis Genitive Case, the existential commitment approach also explains the semantic restrictions on its assignment that have been discussed in Section 2.

Firstly, as noted in Section 2, Irrealis Genitive is only assigned to those NPs that receive a narrow scope reading. This is not surprising under the proposed approach, given that negation and intensional predicates can only cancel existential commitment of those NPs that are interpreted within their scope. An NP that takes wide scope will be interpreted as quantifying over entities in the actual world (or referring to ones, depending on its semantic type), and will carry Absolute (and, therefore, also Relative) Existential Commitment.

Secondly, it has been noted that genitive NPs tend to be indefinite. I believe that there is no inherent incompatibility between Irrealis Genitive and definiteness per se. Rather, definite NPs normally carry existential presupposition. Since NPs that appear in Irrealis Genitive have to lack existential commitment, accusative Case-assignment results. However, under negation, a definite NP can sometimes lose the presupposition of existence, and in that case, it can be assigned Irrealis Genitive. Thus, consider (29).

\section{Petja ne pomnit etot razgovor / etogo razgovora. \\ Petja NEG remember [this talk] (acc sg)/(gen sg) \\ 'Petja doesn't remember this talk.'}

The NP this talk can appear in genitive Case, as long as the sentence does not carry a commitment that the talk in question actually took place. Thus, according to the genitive variant of (29) it is certainly possible that the talk did not take place and that is why Petja cannot remember it. This demonstrates that a definite NP can be assigned Irrealis Genitive, but only as long as it lacks an existential presupposition $^{1}$.

\footnotetext{
${ }^{1}$ In a highly restricted range of environments (primarily in existential sentences), Genitive of Negation can be assigned to definite NPs that do presuppose existence, including proper names. For reasons of space I will not be able to discuss these environments in this paper. To formulate briefly the direction for capturing the facts, I assume, following work by Borshev and Partee, that in existential sentences, existence is always checked relative to a location in a world (and not merely the world as a whole). As a result, existential commitment is also shifted to a commitment that the set an NP quantifies over is not empty in a given location. As a result, NPs that carry
} 
Thirdly, genitive NPs receive non-specific readings. This is to be expected, given that specific NPs generally encode individuals in the actual world. They take wide scope and carry AEC. A possible exception is constituted by such NPs as a unicorn in (17), repeated below:

Mary thinks that a unicorn entered her house.

Under some (though not all) approaches to specificity, this NP is analyzed as specific, as long as Mary is assumed to have a particular unicorn in mind whom she believes to have eaten the petunias. Importantly, even if such an approach to specificity is adopted, we still have to maintain that a specific NP obligatorily carries existential commitment. Thus, although the embedded subject in (17) is not likely to bear AEC, it certainly does carry REC, since the sentence entails that the unicorn exists in those possible worlds that conform to Mary's view of reality. Thus, specific NPs obligatorily carry commitment to existence - most typically, the absolute one, and in some cases possibly the relative one (if they encode a particular entity within the worldview of an individual other than the speaker). In any event, they are predicted to be incompatible with Irrealis Genitive Case, and the prediction is borne out.

\section{Why Is Existential Commitment Important?}

I have argued in the previous section that an NP may appear in Irrealis Genitive if and only if it lacks REC. While this restriction accounts successfully for both the semantic properties of genitive objects and their distribution, a question emerges as to why Case-assignment should be sensitive to such a property as REC. In this final section, I provide a tentative answer to this question, although a more detailed investigation of the issue is still required.

I believe that this property (or rather, its absence) has important consequences for the semantics of the NP. Let us assume, following Montague, that the default interpretation of an NP is intensional, and that it may then receive an extensional reading once embedded in an extensional environment. Let us also assume that bare NPs denote properties (see e.g. Carlson 1977 on English and McNally 2004 on Spanish), again, with the potential to undergo a type-shift if the latter is forced by the environment in which they are merged (see discussion of type-shift in Partee 1986).

Importantly, Russian is a language that lacks articles; therefore, the vast majority of NPs in this language are bare. We will therefore assume that these NPs start out as denoting properties in the intensional sense of the term and are of the semantic type $<\mathrm{s},<\mathrm{e}, \mathrm{t}>>$. Once these NPs undergo a type shift and come to denote objects or sets in a given world (whether the actual one or not), they also receive a commitment to existence in this world. In contrast, an NP that retains its original property, or concept, interpretation will lack existential commitment of 
any type, since its denotation is not restricted to any particular world. Such an NP denotes a function from possible worlds to sets of individuals, and nothing in its semantics eliminates the possibility that in some of these worlds, the value of the function turns out to be an empty set.

Thus, the absence of REC characterizes those NPs that denote properties or concepts, rather than undergoing a type-shift and coming to refer to or quantify over individuals in any given possible world. I propose that only such propertydenoting NPs can appear in Irrealis Genitive Case. This proposal strongly relates to Zimmermann's (1993) analysis, according to which objects of intensional verbs denote properties, and the discussion of this issue in van Geenhoven and McNally (2005). I assume, however, that even an intensionally interpreted NP may be restricted in its denotation to a particular set of possible worlds introduced by the predicate, rather than encoding a property as a whole. It is only when the denotation of an NP is not reduced to any limited set of possible worlds, but rather constitutes the default property interpretation, that Irrealis Genitive Case will be assigned.

\section{References}

Bailyn, John F.: 1997, 'Genitive of negation is Obligatory', in W. Browne, E. Dornisch, N. Kondrashova and D. Zec (eds.) Annual Workshop on Formal Approaches to Slavic Linguistics:The Cornell Meeting, Ann Arbor, Michigan Slavic Publications.

Bailyn, John F.: 2004, 'The Case of Q', in O. Arnaudova et. al. (eds.) Annual Workshop on Formal Approaches to Slavic Linguistics 12, Ann Arbor, Michigan Slavic Publications.

Babyonyshev, Maria: 2003, 'The Extended Projection Principle and the Genitive of Negation Construction', in Sue Brown and Adam Przepiorkowski (eds.) Negation in Slavic, Bloomington, Slavica Publishers.

Borschev, Vladimir and Barbara H. Partee: 2001, 'The Russian Genitive of Negation in Existential Sentences: The Role of Theme-Rheme Structure Reconsidered', in E. Hajieova and P. Sgall (eds.) Travaux de Circle Linguistique de Prague (novelle serie) 4, Amsterdam, John Benjamins Pub. Co.

Borschev, Vladimir and Barbara H. Partee: 2002, 'Genitive of Negation and Scope of Negation in Russian Existential Sentences', talk given at FASL 11.

Brown, Sue: 1999, The Syntax of Negation in Russian: A Minimalist Approach, Stanford, CSLI Publications.

Carlson, G.: 1977, Reference to Kinds in English, Doctoral Dissertation, Umass, Amherst.

Dambriunas, Leonardas: 1980, Introduction to Modern Lithuanian, New York, Franciscan Fathers. 
Dowty, David R., R. E. Wall and Stanley Peters: 1981, Introduction to Montague Semantics, Dordrecht-Boston-London, D. Reidel Publishing Company.

Farkas, Donka F.: 1985, Intensional Descriptions and the Romance Subjunctive Mood, New York, Garland Publishing, Inc.

Farkas, Donka F.: 2003. 'Assertion, Belief and Mood Choice', paper presented at the workshop on Conditional and Unconditional Modality, ESSLLI, Vienna.

Franks, Steven: 1995, Parameters of Slavic Morphosyntax, Oxford, Oxford University Press.

van Geenhoven, Veerle and Louise McNally: 2005, 'On the Property Analysis of Opaque Complements', Lingua 115, 885-914.

Harves, S.: 2002, 'Genitive of Negation and the Syntax of Scope', in M. van Koppen, E. Thrift, E. J. van der Torre and M. Zimmerman (eds.) Proceedings of ConSOLE 9, pp. 96-110.

Heim, Irene: 1992, 'Presupposition Projection and the Semantics of Attitude Verbs', Journal of Semantics 9, 183-221.

Kiparsky, Paul: 1998, 'Partitive Case and Aspect', in M. Butt and W. Geuder (eds.) The Projection of Arguments, Stanford, CSLI Publications.

Kratzer, Angelika: 1981, 'The Notional Category of Modality', in H.J. Eikmeyer and H. Rieser (eds.) Words, Worlds and Contexts, Berlin \& New York, Mouton de Gruyter.

Lunt, Horace Gray: 1955, Old Church Slavonic Grammar, Gravenhage, Mouton.

McNally, Louise: 2004, 'Bare Plurals in Spanish Are Interpreted as Properties', Catalan Journal of Linguistics 3, 115-133.

Nau, Nicole: 1998, Latvian, Munchen, LINCOM Europa.

Neidle, Carol: 1988, The Role of Case in Russian Syntax, Dordrecht, Kluwer Academic Publishers.

Partee, Barbara H.: 1986, 'Noun phrase interpretation and type shifting principles', in J. Groenendijk, D. de Jongh and M. Stokhof (eds.) Studies in Discourse Representation Theory and the Theory of Generalised Quantifiers, Foris, Dordrecht.

Partee, Barbara H. and Vladimir Borschev: 2004, 'The Semantics of Russian Genitive of Negation: The Nature and Role of Perspectival Structure', paper presented at SALT 14.

Pereltsvaig, Asya: 1999, The Genitive of Negation and Aspect in Russian, in Y. Rose and J. Steele (eds.) McGill Working Papers in Linguistics 14, 111-140.

Pesetsky, David M.: 1982, Paths and Categories, Doctoral Dissertation, Cambridge, MIT.

Timberlake, Alan: 1986, 'Hierarchies in the Genitive of Negation', in R. D. Brecht and J. S. Levine (eds.) Case in Slavic, USA, Slavica Publishers, Inc.

Zimmerman, Ede: 1993, 'On the Proper Treatment of Opacity in Certain Verbs’, Natural Language Semantics 1, 149-179. 